\title{
The BECE Grading System Committee Report: Implications for Minimum Educational Qualifications for Basic Education Certificate
}

\author{
Mereku, D. K. \& Akyeampong, A. K. ${ }^{7}$
}

\begin{abstract}
In spite of the low attainment obtained by pupils at the end of primary education in Criterion Referenced Tests (CRT), the performances of these pupils at the end of junior secondary education, as evidenced by results of the Basic Education Certificate Examinations (BECE), were surprisingly normal. Some heads of senior secondary schools (SSS) and concerned educators in the country have observed that there is no match between the apparently high achievement of pupils in the BECE and their performance at the SSS level, and for that reason criticized the validity of the BECE. These criticisms led to the setting up of a committee by the Director General of the Ghana Education Service (GES) to examine the BECE and its grading system and make recommendation for its improvement. The committee found the norm-referenced grading system with the percentage passes already fixed (also referred to as the 'Stanine' system) which was used in the BECE as the major cause of the inefficiencies. It recommended in its place the use of a flexible 9-scale criterion referenced grading system that will reflect variations in the performances of pupils from year to year. The success of the new grading system will depend largely on clearly defined list of grade descriptions for critical grades identified (i.e. Grades 2, 6 and 8). This presentation examines the need to specify the grade descriptions that should match the lowest critical grade (i.e. grade 8), which may be considered as the minimum educational qualifications for basic education.
\end{abstract}

Keyword norm-referenced grading system, stanine' grading system, basic education, minimum basic education qualification

\section{Introduction}

In view of the nation's educational reform programme launched in 1987, the first nine years of schooling, which is free and universal for all children aged normally between 6 and 15 years, is described as basic education. According to the document, 'Report of the Education Commission on Basic Education', 'basic education is the minimum formal education to which every Ghanaian child is entitled as of right, to equip him/her to function effectively in the society" (GMOE, 1986:3).

Basic education connotes the attainment of certain minimum levels of educational goals the mastery of some basic knowledge and skills (Akplu, 1999). The emphasis on junior

${ }^{7}$ Dr. Akyeampong, A. K lectures at the Institute of Education, University of Cape Coast, Ghana and Dr. Mereku, D. K. lectures at the Department of Mathematics Education, University of Education, Winneba. This paper highlights the major findings of the National Committee set up in 1999 to review the Basic Education Certificate Examinations (BECE) grading system. The other members of the committee were Akyeampong, D. A., Legon; Asomaning, W. A., Legon; Addo, B, WAEC; Tingbani, L. T., \& AgyemangDuah, S. (CRDD). The article was written in 2001. 
The BECE Grading System Committee Report: Implications for Minimum Educational Qualifications for Basic Education Certificate Mereku, D. K. \& Akyeampong, A. K.

secondary education in the early part of the reform was therefore to ensure every child is equipped with the essential knowledge and skills that can make him/her develop the ability to function effectively in the society. In other words, the need to make the first half of secondary education comprehensive (i.e. accessible to as many children of schoolgoing age as possible) is to ensure the youth is equipped with the essential knowledge and skills that will make them interact meaningfully with their changing environment and adapt to the advancement in science and technology in the society.

In Ghana, what pupils must experience in basic school in order to acquire these essential knowledge and skills, which are the minimum levels of educational goals each individual is expected of, as a right, are contained in the subjects taught at the junior secondary level. These subjects are Ghanaian Language and Culture, English, Mathematics, Integrated Science, Agricultural Science, Pre-Technical Skills (including Technical Drawing) Environmental Studies, French (optional for schools), Life Skills, Religious/Moral Education, Music \& Dance, and Physical Education.

This suggests the minimum pass levels required in all the subjects should define the criteria for basic education. Minimum educational requirements become synonymous with basic education. Basic education concept therefore embodies a philosophy that has implications for assessment, grading and certification of junior secondary school graduates.

\section{Concerns about Poor Achievement at the Basic Level}

Five years after the Educational Reform Programme initiated in 1987, national tests, designated Criterion Referenced Tests (CRT), were conducted for pupils in the final year in primary education in regions throughout the country. The CRT results from 1992 to 1997 indicated that, on the average, less than 7 per cent of pupils reached a mastery level of 60 per cent in English Language, and less than 3 per cent of them reached mastery level of 55 per cent in mathematics.

In spite of the low attainment observed at the end of primary education, the performance of these pupils at the end of junior secondary education, as evidenced in results of the Basic Education Certificate Examinations (BECE), was surprisingly normal. Some heads of senior secondary schools (SSS) and concerned educators in the country have observed that there is no match between the apparently high achievement of pupils in the BECE and their performance at the SSS level, and for that reason criticized the validity of the BECE. These criticisms led to the setting up of a committee in September 1999 by the Director General of the Ghana Education Service (GES) to examine the BECE and its grading system and make recommendation for its improvement. Prof. D. A. Akyeampong, the chairman of the committee, submitted the committee's findings and recommendations to the Director General in April 2000.

\section{The Old BECE Grading System}

Akyeampong et. al. (2000) observed that the procedure used currently in processing BECE results, that is, the BECE grading scheme, is called the Stanine system, which is a 9-scale standardized grading system. The Stanine is a norm-referenced grading system; 
thus one that allows students to be compared in order to establish a hierarchy of excellence that is used in grading, certification and selection.

Under the Stanine system, grading is related to fixed norms. In other words, proportions of the candidates entered for the examination define the grades and these remain unchanged from year to year, as shown in Table 1.

Table 1 Percentage Number of Candidates Obtaining Each Stanine Grade

\begin{tabular}{cccccccccc}
\hline \multirow{2}{*}{ Year } & Grade & Grade & Grade & Grade & Grade & Grade & Grade & Grade & Grade \\
& $\mathbf{1}$ & $\mathbf{2}$ & $\mathbf{3}$ & $\mathbf{4}$ & $\mathbf{5}$ & $\mathbf{6}$ & $\mathbf{7}$ & $\mathbf{8}$ & $\mathbf{9}$ \\
\hline 1995 & 4 & 7 & 12 & 17 & 20 & 17 & 12 & 7 & 4 \\
1996 & 4 & 7 & 12 & 17 & 20 & 17 & 12 & 7 & 4 \\
1997 & 4 & 7 & 12 & 17 & 20 & 17 & 12 & 7 & 4 \\
1998 & 4 & 7 & 12 & 17 & 20 & 17 & 12 & 7 & 4 \\
1999 & 4 & 7 & 12 & 17 & 20 & 17 & 12 & 7 & 4 \\
\hline
\end{tabular}

Source: Akyeampong, et al., (2000:5)

The Stanine scale is a form of raw score transformation into a scale. The transformed values are assigned the numbers $1,2,3, \ldots 9$, hence the name Stanine, which is the acronym of standard nine. The system provides a type of norm that shows a candidate's position within his/her own cohort in a particular subject for a particular year. From Table 1, it is clear that $77 \%$ of the candidates obtained the Grades 1 - 6 in every subject implying that irrespective of what highest mark or lowest mark in a subject is, this same percentage pass would be obtained yearly.

Besides the ease with which Stanine grades can be computed, the system was found to be the best system that could be used for both certification and selection after the abolition of the common entrance examination in the early years of the Educational Reform.

However, since it is the norm-referenced grading system with the percentage passes already fixed, it was found to have several demerits. Major among these demerits, according to (Akyeampong, et al., (2000) are:

i. It makes it almost impossible to compare candidates' performance and to determine from year to year whether or not there has been a nationwide improvement. For instance, the minimum raw score for the top 4 per cent obtaining Grade 1 in mathematics one year can be $78 \%$, and in another year this can get as low as $56 \%$, and yet 4 per cent of the candidates will still obtain a Grade 1.

ii. It does not reflect steadily rising or declining standards at the basic level, and thus, the results neither reflect improvements in teaching and learning nor in candidates' performances.

The BECE grading system committee therefore recommended in its place the use of a flexible 9-scale criterion referenced grading system that will reflect variations in the performances of pupils from year to year. The new grading system, which was to take effect from the August 2000 BECE, is yet to be used. 
The BECE Grading System Committee Report: Implications for Minimum Educational Qualifications for Basic Education Certificate Mereku, D. K. \& Akyeampong, A. K.

\section{The New BECE Grading System}

Basic Education focuses on broad curriculum goals and the Basic Education Certificate Examination (BECE), an essentially school leaving examination, should assess candidates' achievements across a wide range of content and objectives and so measure what the students have learned within that context (Akyeampong, et. al., 2000). Selection for further education is simply one of the objectives of the BECE. Though the Stanine grading system makes the BECE useful mainly for selection to further education, it provides little information about what the majority of pupils who fail to qualify to the SSS know and can really do, and hence make their placement into other areas of further education and apprenticeship difficult.

The flexible 9-scale criterion referenced grading system recommended in place of the Stanine grading system is based on three key elements:

- Grade Descriptions; i.e. competencies which a candidate obtaining any of the key or critical grades (i.e. grades 2, 6 and 8) should be able to demonstrate;

- Grade Setting; i.e. using Grade Descriptions after marking the examination scripts to advise on scores which will match the critical grades.

- Grade Cut-Off Points; i.e. using the set critical grade scores to determine the cut-off scores for all other grades.

The success of the new grading system depends largely on a clearly defined list of grade descriptions for the key grades. The flexible 9-scale criterion referenced grading system recommended in place of the Stanine grading system can be seen in Table 2.

Table 2 Grade Interpretations in the New Grading System

\begin{tabular}{rlll}
\hline Grade & Interpretation & Grade & Interpretation \\
\hline 1. & Excellent & 6. & Low Average \\
2. & Very Good & 7. & Low \\
3. & Good & 8. & Lower \\
4. & High Average & 9. & Lowest \\
5. & Average & & \\
\hline
\end{tabular}

Source: Akyeampong, et al., (2000:17)

One thing that is obvious from Table 2 is the absence of the grade labeled 'fail'. The interpretation for Grade 9 is now 'lowest'. This is in agreement with current thinking that every child achieves, at least, some basic knowledge and skills by the end of basic education. Labeling a child as a failure is no more acceptable, because it raises questions about who has failed. Is it the child who has failed to attain the basic education, which is his/her right? Or is it the educational system that has failed to provide adequate opportunities for the child to attain this basic right?

\section{Results of the Trial Testing the New Criterion Referenced Grading System}

In order to make a satisfactory transition from the old to newly proposed system, the committee recommended a trial of the procedure to be carried out using the 1999 BECE results. In September 2000, the West African Examinations Council (WAEC) constituted 
Subject Awards Panels to carry out the trial. The panels were made up of Chief examiners and Team leaders of the various subjects as well as subject experts from the Curriculum Research and Development Division (CRDD) of the GES and resource persons from the universities.

At the trial award meeting, grade descriptions were formulated, discussed and documented for the critical grades (i.e. grades 2, 6 and 8). A list of the grade descriptions for three subjects - English, Mathematics and General Science - can be seen in Appendix A. The various subject panels fixed scores for the critical grades using the grade descriptions. The critical grade scores were then used to determine the cut-off scores for all other grades.

Unlike what pertained in the Stanine system, results of the trial test showed marked differences in percentage passes from subject to subject. Using the new criterion referenced grading system, percentage passes at Grades 1 and 9, which were 4\% in either case in the Stanine system, were different as shown in Table 3.

Table 3 Percentage passes at Grades 1 and 9 in the New Grading System

\begin{tabular}{lcccc}
\cline { 3 - 5 } & & English & Mathematics & General Science \\
\cline { 3 - 5 } Grade 1 & New & $\mathbf{0 . 8}$ & $\mathbf{1 . 2}$ & $\mathbf{0 . 5}$ \\
& Stanine & 4 & 4 & 4 \\
Grade 2 & New & 2.3 & 1.3 & 1.6 \\
& Stanine & 11 & 11 & 11 \\
Grade 3 & New & 12.1 & 5.1 & 6.9 \\
& Stanine & 12 & 12 & 12 \\
Grade 8 & New & 17.4 & 9.5 & 9.5 \\
& Stanine & 17 & 17 & 17 \\
Grade 8 & New & 21.8 & 32.8 & 34.2 \\
& Stanine & 7 & 7 & 7 \\
Grade 9 & New & $\mathbf{1 9}$ & $\mathbf{2 6}$ & $\mathbf{2 3}$ \\
\hline Soun & Stanine & 4 & 4 & 4 \\
\hline
\end{tabular}

(Source, WAEC, 2000:3)

Also with new grading system, cumulative percentage passes at Grades 2, 6 and 8, which were fixed as 11\%, 77\% and 96\% respectively in the Stanine system, were completely different as shown in Table 4. 
The BECE Grading System Committee Report: Implications for Minimum Educational Qualifications for Basic Education Certificate Mereku, D. K. \& Akyeampong, A. K.

Table 4 Cumulative percentage passes at Grades 2, 6 and 8 in the New Grading System

\begin{tabular}{llcc}
\hline \multirow{2}{*}{ Subject } & \multicolumn{3}{l}{ Cumulative Percentage Passes } \\
& Grade 2 & Grade 6 & Grade 8 \\
\hline English & 3.1 & 44.1 & 81.0 \\
Mathematic & 2.5 & 23.3 & 73.4 \\
General Science & 2.1 & 24.7 & 76.7 \\
\hline
\end{tabular}

(Source, WAEC, 2000:3)

Table 4 shows that in terms of real attainment in the subjects presented, the majority of the pupils are achieving just the minimum from what the educational system can provide. In mathematics, 53,735 candidates out of the 230,215 that entered the examination (i.e. less than 25\%) of the candidates obtained Grades 1-6. The situation is not very different for General Science.

\section{Validity of the BECE}

The analysis of the 1999 results with the new grading system indicated that in all the subjects the majority of pupils are in the low, lower and lowest grades. This development has several implications for the validity of the BECE. Commenting on this in a recent publication of the Daily Graphic in an article captioned 'The Examinations that Failed', Asante (1996), pointed out that

\footnotetext{
When many students fail an examination, we may blame the students, the teachers or both. We seldom question the examination which failed the students. We take the validity of the examination for granted. But our JSS and SSS examination results suggest that the examinations have on the whole failed us. The examinations have largely failed us because their aims are blurred and their objectives multi-purpose.
}

Our curriculum goals for basic education are not clearly defined. This problem must be confronted. Access, quality and management efficiency, which have been emphasized for some time now, are overall system goals, and there is the need to take a critical look at what should really constitute 'basic education' for now and the future. In other words, there is the need to define what should constitute

- the minimum (or basic) educational qualifications required at the end of junior secondary school; and

- the further educational qualifications that are necessary at the end of junior secondary school for entering senior secondary schools.

Even though grading for the basic education certificate uses both BECE performance and continuous assessment summary, it is not based on any of the above criteria. The BECE uses an assessment scheme that requires students to possess a certain set of knowledge and skills before they can pass. Those who cannot demonstrate their possession of these are failed. The level required to pass is however high, and among those who fail are in fact many who possess a substantial set of attainments which go unrecorded because the minimum educational qualifications required at the end of basic education is not clearly defined. That is, the grade descriptions that should match the lowest critical grade (i.e. Grade 8), which may be considered as the minimum educational qualifications for basic 
education, need to be clearly documented before the BECE can be made to do what it is really intended.

\section{Recommendations for Improving the Validity of the BECE}

The type of assessment scheme required by the comprehensive secondary education system we have in this country today is one which will ensure all students do reasonably well or do not feel failures. It is one that can encourage positive achievement. Positive achievement refers to the actual attainments of the student in a subject. The assessment scheme should enable students to demonstrate what they know, understand and can do rather than what they do not know. To do this, the scheme must ensure that the examinations given match the level of the students' attainments. This can only be done where the minimum educational qualifications required by all is clearly defined and differentiated from those that are necessary for entering senior secondary institutions.

For each subject offered at the JSS level, there must be a list of topics covering the knowledge and skills that can be appropriately learned by all students at this level. The appropriateness of this list should be related not only to the students' ability to cope with the content but also to what will be useful in the future for the majority of students whose formal education is likely terminate at this level. Such a list may be called the core curriculum of the subject at a particular level.

Sometimes the term core curriculum is used when referring to all the subjects at a particular level. The core curriculum in this case is the compulsory subjects that all the students studying at a particular level are required to take. The secondary curriculum can be likened onto a mango fruit. The central part of this fruit is the core, which contains the seed. On the core is the flesh, which contains the sweet yellow juice that we suck.

Similarly, the curriculum can be said to comprise a core content and additional content. The core curriculum content is analogous to the basic list of topics covering the knowledge and skills that can be appropriately learned by all. At the junior secondary school (JSS) level, the basic list must contain a list of items that indicate the minimum level of performance expected of any student completing school at this level. This is what curriculum experts actually refer to as the core content (or core curriculum) in a subject.

For the purpose of assessment, the core curriculum at the junior secondary level should comprise knowledge and skills considered appropriate for students in about the lowest 40 per cent of the range of attainment. At the JSS level, these are students who normally would not have attempted any form of secondary education had it not been the reforms in education. They are students who would have found it impossible to get into secondary education since they could not have passed the competitive common entrance examination, which was stopped as a result of the reform. The students in the lowest 40 per cent of the ability range in JSS should therefore not be bothered too much with what those who would eventually pass to senior secondary should be able to do.

There is the need for both natural and social scientists of the nation to begin to think of what should constitute basic knowledge in all basic subjects. The GES should make its position clear on what every child really needs, and is capable of doing, in science in order to contribute his/her quota to the development of this country. Such minimum 
The BECE Grading System Committee Report: Implications for Minimum Educational Qualifications for Basic Education Certificate Mereku, D. K. \& Akyeampong, A. K.

knowledge and skills that are essential not only to ensure the individual's survival in society, but also his/her ability to contribute to the development of the society, is the culmination of what may be described as 'basic education'.

The practice (or traditional model of curriculum development) where a few educators are handpicked and camped for a couple of weeks to prescribe what should go into the basic school curriculum is of little value. The result is that the official basic school curriculum is of little relevance to the needs of the majority of pupils terminating their formal education at this level. Table 5 is the grade descriptions used by the Mathematics award panel in testing the new grading system.

Table 5 Trail BECE Standard Fixing and Subject Grade Awards: Mathematics Grade Descriptions

\begin{tabular}{cl}
\hline GRADE & D E S C R I P T I O N \\
\hline 8 & $\begin{array}{l}\text { The candidate should have an idea of numbers and be able to carry out the basic } \\
\text { four operations on them. The candidate should apply the idea of numbers to } \\
\text { measurement and identify shapes. }\end{array}$ \\
In grade 6, the candidate should be able to translate simple word problems \\
involving single idea into mathematical sentences and solve them using a \\
combination of the basic operations. The candidate should be able to demonstrate \\
the need for accuracy in measurements, translate mathematical ideas/concepts \\
pictorially and identify shapes and their properties.
\end{tabular}

The competencies described under Grades 8 (i.e. what the majority of pupils who are likely to terminate their formal education should score) are too sketchy. Many educators here are in the field, interact and/or see how most of our youth who had no tertiary education live and carry out their economic/everyday life activities. We are therefore the right body to support the Curriculum Research and Development Division of the GES and WAEC to list all the necessary knowledge and skills that are required to make the Ghanaian child numerate and literate in the twenty-first century.

\section{Conclusion}

An assessment scheme that is intended to test for minimum competency cannot at the same time do a good job in selecting students for higher academic pursuits. An assessment scheme for testing for minimum competency should utilize both a criterionreferenced testing and grading system. Therefore your input on what should constitute minimum scientific knowledge and skills that are essential for the development of basic education will be very appreciated to make our educational system more functional. There is need to constitute new subject panels to tackle the question of the minimum qualifications in each subject; and There is need to adopt an assessment system that will ensure that every child attains his/her 'basic education'.

[The writer was in the 6-member BECE Grading System Committee] 


\section{References}

Akplu, H. F. (1999) To Use or Not to Use the Stanine Grading System for the BECE? A Memo to the Committee Reviewing the Grading System for the BECE. p2.

Akyeampong, D. A., Asomaning, W. A., Akyeampong, A. K., Mereku, K., Tingbani, L. T., Addo, B, \& Agyemang-duah, S. (2000) Report of the Committee to review the Basic Education Certificate Examinations (BECE) grading system, Accra: Curriculum Research and Development Division of the Ghana Education Service.

Asante K. B. (1996) 'The Examinations that Failed’ Daily Graphic March 11, 1996.

GMOE - Ghana Ministry of Education, (1986) Report of the Education Commission on Basic Education. Accra: Ghana Publishing Cooperation. p9.

WAEC - West African Examinations Council - (2000) Trial BECE Standard Fixing and Grade Awards, Accra: Test Development Division of the West African Examinations Council.

\section{APPENDIX A}

TRAIL BECE STANDARD FIXING AND SUBJECT GRADE AWARDS

Grade Descriptions English Language

GRADE D E S C R I P T I O N

8 A candidate within this grade should be able to understand and carry out simple instructions in the language.

To get this grade the candidate should be able to understand and use the

6 language in its simplest form. He/she or she should be able to express himself or herself using the basic structures.

This candidate should have a good control of the English Language.

$2 \mathrm{He} / \mathrm{she}$ should be able to understand, interpret and communicate effectively using appropriate registers, idiomatic expressions and varied sentence structures. 
The BECE Grading System Committee Report: Implications for Minimum Educational Qualifications for Basic Education Certificate Mereku, D. K. \& Akyeampong, A. K.

\section{Trail BECE standard fixing and subject grade awards}

\section{Grade Descriptions: General Science}

\begin{tabular}{cll}
\hline \multirow{2}{*}{ GRADE } & \multicolumn{2}{c}{ DESCRIPTION } \\
\hline \multirow{3}{*}{8} & a. & Definitions \\
& b. & Measurements and units \\
& c. & Knowledge of common diseases in Ghana and their prevention. \\
& a. & State differences and similarities. \\
& b. & Draw and label diagrams \\
6 & c. & State basic functions \\
& d. & Explanation of basic terms \\
& e. & Description of processes \\
& f. & Simple classifications (e.g. living things and non-living things; acids and bases) \\
& a. & Classification (e.g. levers, metals and non-metals, reactive and non-reactive \\
& metals) \\
& b. Demonstration of concepts \\
& c. Perform calculations accurately \\
& d. & Explanation of principles and underlying concepts \\
e. & Write and balance chemical equations.
\end{tabular}

